\title{
Future Aeronautical Communications: The Data Link Component
}

\author{
Nikos Fistas \\ EUROCONTROL ${ }^{1}$ \\ E.U.
}

\section{Introduction}

This chapter presents an overview of the European activities in relation to the future aeronautical communications and in particular the new data link components. It presents the origins of the work, summarising the previous activities and it describes the three new data links that are being considered as well as the relevant activities undertaken in Europe. In addition, it briefly describes the airborne integration and the transition challenges that need to be investigated and resolved.

The content of this chapter is based on an article that was first published in the EUROCONTROL Skyway Magazine, No 54, in December 2010.

\section{Background}

The origin of the EUROCONTROL sponsored investigations concerning the future aeronautical communications can be traced back to ICAO's 11th Air Navigation Conference (AN-Conf/11) in 2003 (ICAO AN-Conf/11, 2003).

In its conclusions, AN-Conf/11 agreed that the aeronautical mobile communication infrastructure had to evolve in order to accommodate new functionalities and to provide the adequate capacity and quality of service required to support evolving air traffic management (ATM) requirements within the framework of the global ATM operational concept. Accordingly, the conference developed recommendations addressing the need for an evolutionary approach while ensuring the global interoperability of air/ground $(\mathrm{a} / \mathrm{g})$ communications, and requesting the investigation of the technology alternatives for future a/g communications and the standardisation of those selected.

The conference discussions stressed the requirement to maximise the use of systems already implemented, and highlighted the particular attention to be given to the careful utilisation of the (limited) available spectrum as well as to the appropriate consideration of transition aspects. In conclusion, the AN-Conf/ 11 emphasised the need for international cooperation, particularly in the field of air/ground communications.

In line with the conference recommendations, EUROCONTROL and the US Federal Aviation Administration (FAA) decided to establish a dedicated working arrangement

${ }^{1}$ The presented information expresses the views of the author and does not necessarily reflect EUROCONTROL's official policy. 
(Action Plan 17 of the EUROCONTROL-FAA Memorandum of Cooperation) to carry out this work (EUROCONTROL/FAA Action Plan 17, 2007).

The Action Plan 17 (AP17) activities have been very closely coordinated with ICAO's Aeronautical Communications Panel (ACP) to facilitate global harmonisation. AP17 was a joint activity between FAA/NASA and EUROCONTROL. In Europe, France, Germany, Spain, Sweden and the UK have also been actively supporting and contributing to the European investigations. The AP17 work was concluded in 2007 and the outcome was used to plan the future activities in the context of the SESAR and NextGEN projects.

In Europe, the future communications infrastructure (FCI) work is now carried out in the context of the SESAR Programme, which will oversee the development of the required new generation of technological systems, components and operational procedures to support the future concepts as defined in the SESAR ATM Master Plan and Work Programme.

A key outcome of the AP17 activities was that there is no single technology which meets all expected future requirements across all operational flight domains. In addition to the importance of maximising the use of the existing infrastructure, the need to introduce technologies driven by clear operational requirements linked to tangible benefits, led to the conclusion that the FCI should be a "system of systems", integrating existing and new technological components. FCI should secure seamless continuation of operations supporting the current and future requirements, to safeguard investments in infrastructure and equipage, and to facilitate the required transitions.

In summary, the FCI work is built on the following assumptions:

- In the future operating concept, data becomes the primary mode of communications (voice will remain available for emergency communications).

- In the event of failure of data communications, voice is unlikely to be able to sustain operations at the same capacity level. Consequently, different data links may be needed in order to maintain capacity of operations.

- The future (2020+) system needs to support ATS (air traffic services) and AOC (airline operational communications) end-to-end communications, including ground/ground, air/ground and air/air.

The AP17 activities focused on air/ground data communications and analysed many candidate technologies. The technology investigations led to the following three proposals for new wireless data communications system developments (see Figure 1):

1. a ground-based, high-capacity, airport surface data link system, referred to as the aeronautical mobile airport communications system (AeroMACS);

2. a ground-based data link system for continental airspace in general, referred to as the Lband digital aeronautical communications system (LDACS);

3. a satellite-based data link system for the oceanic, remote (deserted) and continental environments (in the latter case complementing the terrestrial systems).

While for AeroMACS (the aeronautical mobile airport communications system), a specific existing standard has already been identified, for the other two technology developments, AP17 recommended further activities, to finalise the technical investigations and the selection and standardisation of the proposed systems.

It is important to note that a significant constraint in the technology investigations for aviation is the spectrum to be used. Communications supporting ATM exchanges fall into the category of "safety of life" communications, and as a result they have a special protection status in order to avoid interference.

However, this protection is applicable only to specific bands, and effectively there are three such bands: the VHF band, the L band and the C band. In Europe, the VHF band is a very 
congested band, and there is no room for additional systems to operate. The VHF band was therefore not considered for use by any of the new systems, leaving the other two bands as the only candidates.

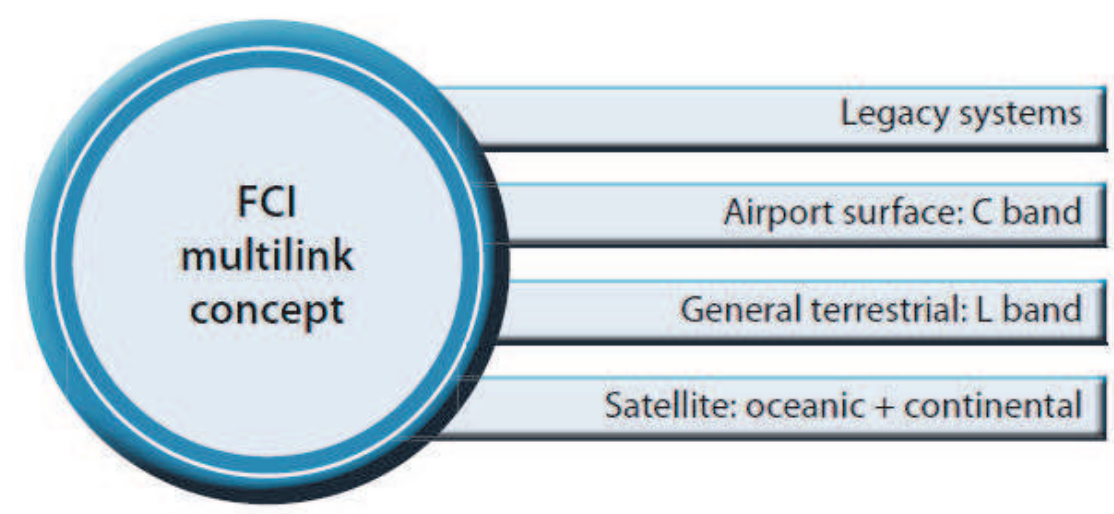

Legacy systems and new datalinks

Fig. 1. FCI Multilink Concept.

\section{Airport surface system: AeroMACS}

AeroMACS is intended to support on-the-ground communication exchanges, particularly at busy airports. Whilst the aim is to support both ATS and AOC applications, it is expected that the AOC applications may be the driving element in the initial system implementations in Europe. In addition, especially in the US, the same standard is also being considered to support other aviation applications on the airport surface.

Considering the expected significant volumes of information to be carried and the short distances to be covered while the aircraft is on the ground, the aeronautical $\mathrm{C}$ band $(5 \mathrm{GHz})$ has been selected, and an appropriate allocation for $A M(R) S$ (aeronautical mobile route service allocation) was obtained by the International Telecommunication Union (ITU) in 2007. AeroMACS is based on the IEEE 802.16 WiMAX mobile communications standard, in order to benefit from commercial general telecom developments and minimise the required development resources.

In SESAR, there are two projects (P15.2.7 and P9.16) supporting the development of the AeroMACS system. These two projects aim to define and validate an international global aviation standard. The two projects will carry out analysis, simulations and testing, involving purpose-built system prototypes.

Project 15.2.7 addresses the overall system aspects and focuses on the ground system component, whilst project P9.16 focuses on the aircraft system aspects and investigates the airborne integration of the AeroMACS system.

In Europe, in addition to the SESAR projects, there is also the EU FP7 SANDRA project (SANDRA, 2009) that is actively pursuing the AeroMACS development. The SANDRA activities are closely coordinated with the SESAR projects activities aiming to avoid 
duplication and maximise synergies. The AeroMACS development is also actively being pursued in the US supported by FAA/NASA.

Standardisation of AeroMACS is currently taking place in two closely cooperating groups in the European Organisation for Civil Aviation Equipment, EUROCAE, (WG82) (EUROCAE WG-82, 2010) and the US Radio Technical Commission for Aeronautics, RTCA, (SC223) (RTCA SC-223, 2010). These two groups are working on the development of the aviationspecific profile of the WIMAX standard to describe AeroMACS, and in the future the groups will also address the development of additional material (MOPS 2 and MASPS3).

In March 2011, the two groups converged on a joint proposal to WiMax Forum for the aviation profile. The features of this profile are now the basis for the development of prototypes in the context of SESAR and SANDRA activities in order to validate the profile and support the development of the required standards.

While EUROCAE and RTCA will cover the technical details of the proposed system, ICAO is also expected to be involved in the standardisation process, with high level documents such as SARPs ${ }^{4}$. A dedicated ICAO working group (WG S) has been formed under the Aeronautical Communications Panel (ACP) to develop the required ICAO documents, building upon the EUROCAE and RTCA relevant work.

\section{Terrestrial air / ground system: LDACS}

LDACS is a ground-based system using line-of-sight communications to support air/ground communication, in particular for en-route and TMA communications in continental airspace. The LDACS system is targeting operations in the L- band $(1 \mathrm{GHz})$. This band is heavily utilised by navigation and surveillance aviation systems. However, considering the need to communicate over significant distances, the L-band was identified as the best compromise candidate band, primarily because of its acceptable propagation characteristics. A co-primary AM(R)S allocation was obtained from the ITU in 2007, which means that LDACS should not interfere with the other primary users of the band (navigation and surveillance systems).

The spectrum compatibility analysis is critical for LDACS and has to work in both directions: first not to hinder the operation of existing systems, but also to be able to operate in the presence of existing systems.

The AP17 investigations did not identify a commercially utilised system meeting all requirements, so they proposed to define a system based on features of some existing systems and reuse of previous developments. Following a trade-off analysis, two options for the LDACS were identified.

The first option (LDACS1) represents the state of the art in the commercial developments employing modern modulation techniques, and may lead to utilisation/adaptation of commercial products and standards. LDACS1 is based on a frequency division duplex (FDD) configuration utilizing OFDM modulation techniques, reservation based access control and advanced network protocols. This solution is a derivative of the B-AMC and TIA-902 (P34) technologies.

\footnotetext{
2Minimum Operational Performance Standards

${ }^{3}$ Minimum Aviation System Performance Specifications

4Standards And Recommended Practices
} 
The second option (LDACS2) capitalises on experience from current aviation systems and standards such as VDL35, VDL46 ${ }^{6}$ and UAT7. LDACS2 is based on a time division duplex (TDD) configuration utilizing a binary modulation derivative of the implemented UAT system (CPFSK family) and existing commercial (e.g. GSM) systems and custom protocols for lower layers providing high quality-of-service management capability. This solution is a derivative of the LDL and AMACS technologies. The table below depicts the characteristics of the two options.

\begin{tabular}{|c|c|c|c|}
\hline & Access scheme & Modulation type & Origins \\
\hline LDACS1 & FDD & OFDM & B-AMC, TIA 902 (P34) \\
\hline LDACS2 & TDD & CPFSK/GMSK type & LDL, AMACS \\
\hline
\end{tabular}

Table 1. LDACS (the L-band data link) candidates' key characteristics

The two LDACS options need further analysis, especially in terms of the spectral compatibility, before one of them is finally selected.

In SESAR, project P15.2.4 (Future Mobile Data Link system definition) is tasked with investigating the proposed LDACS options, selecting the most appropriate one, and developing the required standards. While some activities (Early Tasks) of the project are already ongoing, the full project activities will be starting in the second half of 2011.

The key tasks for the LDACS investigations are to define the interference environment and the criteria for the spectrum compatibility analysis. For these investigations, there will be development of prototypes and test beds to perform the required testing in a representative environment in order to validate the previous theoretical investigations and analysis carried out.

To ensure worldwide interoperability, the selected LDACS system will require global standards, which means that the decision for the LDACS system needs to be taken in the ICAO framework. Consequently, coordination with all other interested regions, such as the US, is very important. This is currently progressed under Action Plan 30, which has been established to continue the AP17 coordination. In the future, there will be a dedicated Coordination Plan addressing the cooperation between SESAR and NextGen under the EU /US Memorandum of Cooperation.

\section{New satellite communication system}

Satellite communications are very well placed to cover the large oceanic and remote airspaces. Currently, there are two ICAO standards for satellite communications, the INMARSAT3 and IRIDIUM systems. However, the performance requirements in the current ICAO satellite standards (AMS(R)S SARPs) are insufficient to cover the quality of service (QoS) requirements of the applications supporting the future operating concept. There is therefore a need to update the satellite SARPs to include more stringent performance requirements, to select a new technology and to develop the required standards to meet the updated requirements.

5VHF Digital Link 3

${ }^{6}$ VHF Digital Link 4

${ }^{7}$ Universal Access Transceiver 
The need to select a new technology does not constitute an undesirable proliferation of technologies, as by the 2020+ timeframe all current aviation satellite systems will be reaching the end of their lifetime and new systems will have to be reconsidered in order to continue supporting the oceanic areas.

Furthermore, in order to support the new operating concepts, it is anticipated that multiple data links will be required to meet availability and other QoS requirements. It is therefore proposed that the satellite system should also be considered for use in continental airspace jointly with the terrestrial based systems to make it easier to meet the application requirements.

In Europe, the European Space Agency (ESA) has established the Iris project to facilitate the development of the future aviation satellite system. Iris is composed of technology studies such as ANTARES and THAUMAS investigating specific technical solutions. ANTARES is investigating the development of a new satellite communication system and THAUMAS is investigating the required evolution of the current INMARSAT Swiftbroadband system. In addition, Iris is also undertaking service provision studies investigating the suitable/likely model that is to be considered for the future satellite communication system.

The Iris programme is complemented by the SESAR P15.2.6 project (Future Satellite Communication system). The SESAR project focuses on the identification of the requirements, will support validation and verification activities in coordination with Iris and will undertake the required standardisation activities. In particular, the project will support the development of the required global ICAO standards in terms of SARPs and Technical Manuals.

The international aspect of satellite system standardisation is dealt with in a dedicated group, the NEXUS group, with voluntary contributions from all interested parties in Europe or outside (EUROCONTROL NEXUS). The first task of the group (technology independent) is to develop a coordinated proposal to ICAO for an updated version of the AMS(R)S SARPs with stringent performance requirements. In the future, the NEXUS group will continue with the development of a proposal for an ICAO Technical Manual describing a proposed system that will be meeting the performance requirements of the updated SARPs.

\section{Airborne integration and transition considerations}

As shown in Figure 2, if all the considered new data links will be implemented, then the future aircraft will have to support many and different communication modes. However it is already clear, that it will not be acceptable that the introduction of these new systems will imply the airborne integration of dedicated and standalone radio equipment and antennas. In addition to the weight and space limitations on the aircraft, the interference aspects make this option impossible to pursue.

Therefore the proposed new system developments need to be coupled with a new approach in order to address the airborne integration questions. The proposed Future Communications Infrastructure will only be feasible if a flexible airborne architecture is made possible. For such architecture, there are new promising technological developments that need to be considered. The use of software radios and the sharing of antennas or use of antennas able to operate in multiple frequency bands is a research field that needs further investigation.

In SESAR, project P9.44 (Flexible Communication Avionics) has two objectives. The first one is to investigate the technical and business feasibility and to identify solutions of new on- 
board flexible radio architectures and equipment (such as, but not limited to, Software Defined Radio) which could support several or even all the future and legacy communication elements. The second objective, following an encouraging feasibility analysis will be to develop prototypes of candidate solutions for new on-board flexible radio equipment and to validate the appropriateness of this new technology as constituent of future certified avionics systems.

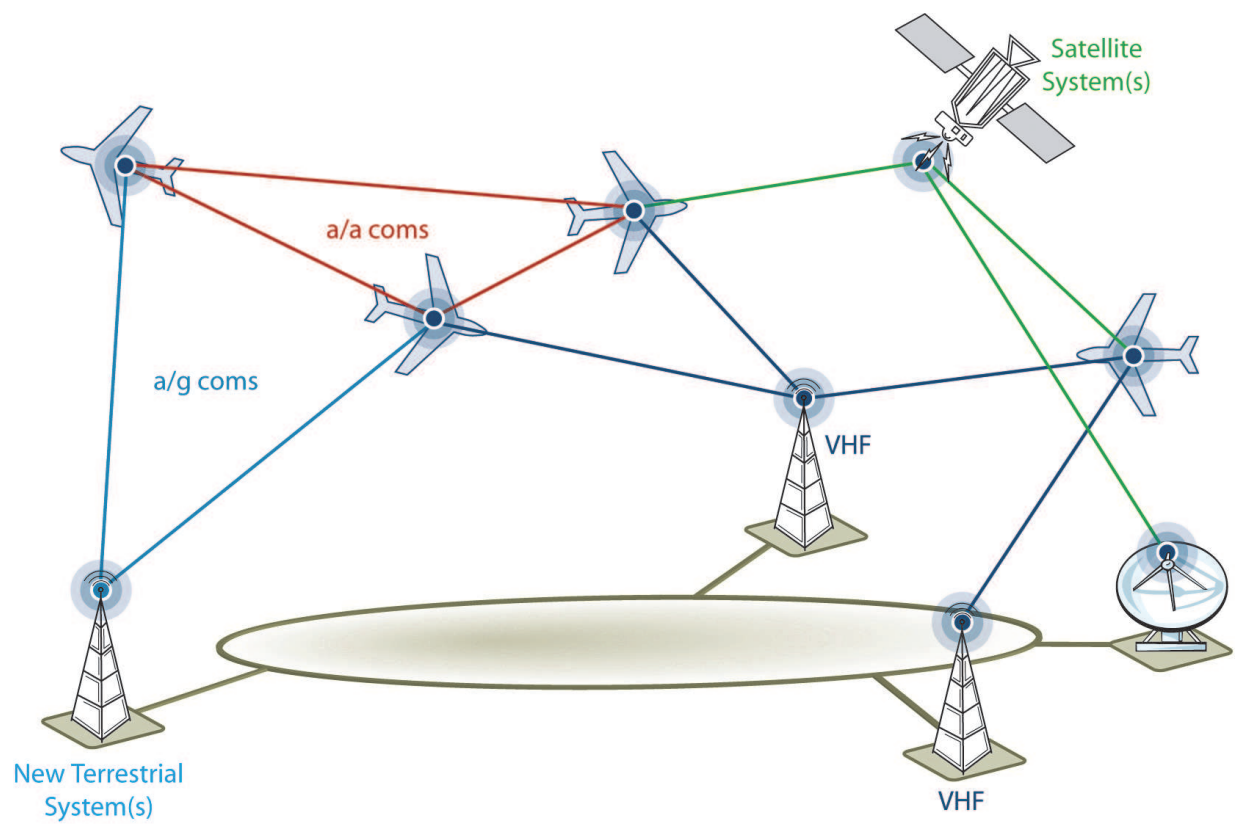

Fig. 2. FCI - a potential scenario for $2020+$.

Another critical aspect that needs to be carefully addressed is the transition from the current to the future system. It is relatively easy to integrate the new technologies on new aircraft (forward fit) however retrofitting existing aircraft can be a challenging and sometimes an impossible task.

Therefore different scenarios need to be analysed in order to facilitate the implementation of the future systems. These scenarios need to ensure the optimisation of the use of the current (legacy) systems and only require the use of the new technologies for capabilities not being able to be supported by the legacy systems.

\section{Conclusions}

While significant work and achievements have already been accomplished, a lot of work remains to be done. Developing new technology solutions for aviation is a very lengthy and expensive process. There are many different factors which need to be properly aligned in order to bring about the successful implementation of a new system. Above all, any new system needs to be justified by new operational procedures and applications meeting future requirements. 
New systems in aviation carry significant new costs for installation, and also additional costs for operation and maintenance, and they have to be offset by clear and measurable benefits. The proposed data links in the future communications infrastructure are not the drivers of the developments. They are the enablers of the required new concepts. However, in recognition of the long timescales required to introduce new systems in aviation, work needs to start many years in advance. The challenge in aviation is to select systems to be widely implemented at least a decade later, but which will remain capable of meeting evolving requirements.

In the technology development process, the international coordination is one of the prerequisites of success. It is critical to work with all interested parties from all regions. Timely availability of mature global standards will be critical in decision-taking and system implementation. EUROCONTROL is committed to working closely with ICAO and other interested parties to ensure that the appropriate systems are available to support the emerging concepts and operational requirements of the future $4 \mathrm{D}$-trajectory-based operations.

\section{References}

EUROCAE WG-82. Working Group 82, Mobile Radio Communication Systems: Airport Surface Radio Link (WIMAX Aero), Info available at: www.eurocae.net/workinggroups/wg-list/50-wg-82.html

EUROCONTROL/FAA Action Plan 17. (2007). Final Conclusions and Recommendations Report, Version 1.1, EUROCONTROL/FAA/NASA, November 2007, Available at: www.eurocontrol.int/communications/public/standard_page/General_FCI_ Library.html

EUROCONTROL NEXUS. Information available at: www.eurocontrol.int/nexsat/public/standard_page/NEXUS.html

ICAO AN-Conf/11 (2003). Proceedings of Eleventh ICAO Air Navigation Conference, October 2003, Available at: www.icao.int

Iris. Satellite-based communication solution for the Single European Sky Air Traffic Management Research programme - Element 10 of the ESA ARTES programme, Info available at: www.telecom.esa.int/iris

NextGen. Next Generation Air Transportation System (NextGen), Info available at: www.faa.gov/nextgen

RTCA SC-223. Special Committee SC-223, Airport Surface Wireless Communications, Info available at: http://www.rtca.org/comm/Committee.cfm?id=133

SANDRA. Seamless Aeronautical Networking through integration of Data links Radios and Antennas (SANDRA), Info available at: www.sandra.aero

SESAR. Single European Sky ATM Research Programme (SESAR) Joint Undertaking, Info available at: www.sesarju.eu 


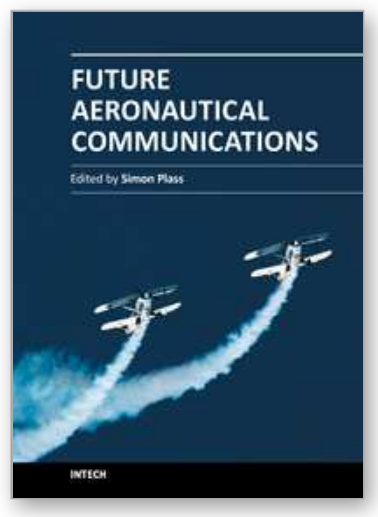

\author{
Future Aeronautical Communications \\ Edited by Dr. Simon Plass
}

ISBN 978-953-307-625-6

Hard cover, 378 pages

Publisher InTech

Published online 26, September, 2011

Published in print edition September, 2011

There are well-founded concerns that current air transportation systems will not be able to cope with their expected growth. Current processes, procedures and technologies in aeronautical communications do not provide the flexibility needed to meet the growing demands. Aeronautical communications is seen as a major bottleneck stressing capacity limits in air transportation. Ongoing research projects are developing the fundamental methods, concepts and technologies for future aeronautical communications that are required to enable higher capacities in air transportation. The aim of this book is to edit the ensemble of newest contributions and research results in the field of future aeronautical communications. The book gives the readers the opportunity to deepen and broaden their knowledge of this field. Todayâ $€^{\mathrm{TM}} \mathrm{S}$ and tomorrowâ€ $€^{\mathrm{TM}} \mathbf{S}$ problems / methods in the field of aeronautical communications are treated: current trends are identified; IPv6 aeronautical network aspect are covered; challenges for the satellite component are illustrated; AeroMACS and LDACS as future data links are investigated and visions for aeronautical communications are formulated.

\title{
How to reference
}

In order to correctly reference this scholarly work, feel free to copy and paste the following:

Nikos Fistas (2011). Future Aeronautical Communications: The Data Link Component, Future Aeronautical Communications, Dr. Simon Plass (Ed.), ISBN: 978-953-307-625-6, InTech, Available from:

http://www.intechopen.com/books/future-aeronautical-communications/future-aeronautical-communicationsthe-data-link-component

\section{INTECH}

open science | open minds

\section{InTech Europe}

University Campus STeP Ri

Slavka Krautzeka 83/A

51000 Rijeka, Croatia

Phone: +385 (51) 770447

Fax: +385 (51) 686166

www.intechopen.com

\section{InTech China}

Unit 405, Office Block, Hotel Equatorial Shanghai

No.65, Yan An Road (West), Shanghai, 200040, China

中国上海市延安西路65号上海国际贵都大饭店办公楼 405 单元

Phone: +86-21-62489820

Fax: $+86-21-62489821$ 
(C) 2011 The Author(s). Licensee IntechOpen. This chapter is distributed under the terms of the Creative Commons Attribution-NonCommercialShareAlike-3.0 License, which permits use, distribution and reproduction for non-commercial purposes, provided the original is properly cited and derivative works building on this content are distributed under the same license. 